\title{
Oral administration of phytocomponent $p$-hydroxycinnamic acid has a preventive effect on bone loss in streptozotocin-induced diabetic rats
}

\author{
MASAYOSHI YAMAGUCHI, SATOSHI UCHIYAMA and YING LING LAI \\ Laboratory of Endocrinology and Molecular Metabolism, Graduate School of Nutritional Sciences, \\ University of Shizuoka, 52-1 Yada, Suruga-ku, Shizuoka 422-8526, Japan
}

Received December 29, 2006; Accepted February 8, 2007

\begin{abstract}
The phytocomponent $p$-hydroxycinnamic acid (HCA) has been shown to have a stimulatory effect on bone formation and an inhibitory effect on bone resorption in rat femoral tissues in vitro. The preventive effect of HCA on bone loss induced in streptozotocin (STZ)-diabetic rats was investigated in vivo. Rats received a single subcutaneous administration of STZ (6.0 mg/100 g body weight), and then the animals were orally administered HCA $(0.25,0.5$, or $1.0 \mathrm{mg} / 100 \mathrm{~g}$ body weight) once daily for 14 days. STZ administration caused a significant decrease in body weight and a significant increase in serum glucose, triglyceride, and calcium levels, indicating a diabetic state. These alterations were significantly prevented by administration of $\operatorname{HCA}(0.25$, 0.5 , or $1.0 \mathrm{mg} / 100 \mathrm{~g}$ ). Calcium content in the femoraldiaphyseal and -metaphyseal tissues was significantly decreased in STZ-diabetic rats. This decrease was significantly prevented after administration of HCA $(0.25,0.5$, or $1.0 \mathrm{mg} /$ $100 \mathrm{~g}$ ). Alkaline phosphatase activity in the diaphyseal and metaphyseal tissues was significantly decreased in STZdiabetic rats. The decrease in diaphyseal alkaline phosphatase activity in STZ-diabetic rats was significantly prevented after administration of HCA $(0.5$ and $1.0 \mathrm{mg} / 100 \mathrm{~g})$. The diaphyseal DNA content was also significantly decreased in STZdiabetic rats. Administration of $\mathrm{HCA}(0.25,0.5$, or $1.0 \mathrm{mg} /$ $100 \mathrm{~g}$ ) caused a significant increase in DNA content in the diaphyseal and metaphyseal tissues in STZ-diabetic rats. This study demonstrates that the intake of HCA has preventive effects on bone loss in STZ-diabetic rats, and that the intake has partially restorative effects on serum biochemical findings in the diabetic state.
\end{abstract}

Correspondence to: Dr Masayoshi Yamaguchi, Laboratory of Endocrinology and Molecular Metabolism, Graduate School of Nutritional Sciences, University of Shizuoka, 52-1 Yada, Suruga-ku, Shizuoka 422-8526, Japan

E-mail: yamaguch@u-shizuoka-ken.ac.jp

Key words: diabetes, bone metabolism, osteoporosis, $p$-hydroxycinnamic acid, rat femur

\section{Introduction}

Bone loss with aging induces osteoporosis, which is widely recognized as a major public health problem (1-4). A decrease in bone mass leads to bone fracture; bone loss may be due to decreased bone formation and increased bone resorption. Pharmacologic and nutritional supplements may prevent bone loss with increasing age (5-7). Chemical factors in food and plants may have a useful role in the prevention of osteoporosis with aging.

Cinnamic acid is present in many plants. $p$-hydroxycinnamic acid (HCA) is an intermediate-metabolic substance found in plants and is synthesized from thyrosine. The physiologic role of HCA has not been fully clarified, although the compound has an effect as an anti-oxidant $(8,9)$. More recently, it has been found that among cinnamic acid and other related compounds, HCA has a unique-anabolic effect on bone metabolism (10). HCA has a stimulatory effect on bone formation and an inhibitory effect on bone resorption in rat femoral tissues in vitro (10). HCA has been shown to suppress various bone resorption-stimulating factor-induced osteoclast-like cell formations in mouse bone marrow culture in vitro (11). Oral administration of HCA has an anabolic effect on bone components in the femoral tissues of rats in vivo (12). HCA may have a role in the prevention of osteoporosis with aging. This, however, has not yet been clarified.

This study was undertaken to determine whether the intake of HCA has a preventive effect on bone loss induced in the diabetic state (13). We found that HCA had a preventive effect.

\section{Materials and methods}

Chemicals. Streptozotocin (STZ) was purchased from Sigma Chemical Co. (St. Louis, MO, USA). Hydroxycinnamic acid (HCA) and other chemicals were of reagent grade from Sigma Chemical Co. and Wako Pure Chemical Industries (Osaka, Japan).

Animals. Male Wistar rats (conventional) weighing 110-120 g (5 weeks old) were obtained from Japan SLC (Hamamatsu, Japan). The animals were fed commercial laboratory chow (solid) containing $1.1 \%$ calcium and $1.1 \%$ phosphorus and housed at a room temperature of $25^{\circ} \mathrm{C}$ with free access to distilled water. 
Administration procedure. STZ was dissolved in $50 \mathrm{mM}$ sodium citrate $(\mathrm{pH} 4.5)$ solution containing $150 \mathrm{mM} \mathrm{NaCl}$ (14). The solution $(6.0 \mathrm{mg} / 0.5 \mathrm{ml} / 100 \mathrm{~g}$ body weight) was subcutaneously administered to rats, and 14 days later the animals were sacrificed by exsanguination. HCA was dissolved in corn oil as a concentration of $0.5,1.0$ or $2.0 \mathrm{mg} /$ ml. HCA $(0.25,0.5$, or $1.0 \mathrm{mg} / 0.5 \mathrm{ml} / 100 \mathrm{~g}$ body weight) was orally administered to rats through a stomach tube once daily for 14 days. HCA was orally administered $3 \mathrm{~h}$ after the administration of STZ $(6.0 \mathrm{mg} / 100 \mathrm{~g})$. Rats were sacrificed $24 \mathrm{~h}$ after the last administration of HCA, and the blood and femur were removed immediately.

Analytical procedures. Blood samples obtained by cardiac puncture were centrifuged $30 \mathrm{~min}$ after collection, and the serum was separated. Serum was frozen at $-80^{\circ} \mathrm{C}$ until assay. Serum glucose, triglyceride, calcium, and inorganic phosphorus concentrations were determined using an assay kit (Wako Pure Chemical Industries).

The diaphyseal or metaphyseal tissues were dried for $16 \mathrm{~h}$ at $110^{\circ} \mathrm{C}$. Calcium was determined using atomic absorption spectrophotometry (15). Calcium content in bone tissues was expressed as milligrams per gram of dry bone.

To assay alkaline phosphatase activity, the diaphyseal or metaphyseal tissues were immersed in $3.0 \mathrm{ml}$ of ice-cold barbital buffer $6.6 \mathrm{mM}$ ( $\mathrm{pH} 7.4$ ), cut into small pieces, and disrupted for $60 \mathrm{sec}$ with an ultrasonic device. The supernatant centrifuged at $600 \mathrm{x}$ g for $5 \mathrm{~min}$ was used to measure enzyme activity. Enzyme assay was carried out under optimal conditions. Alkaline phosphatase activity was determined using the method of Walter and Schutt (16). Enzyme activity was expressed as micromole of $p$-nitrophenol liberated per minute per milligram of protein. Protein concentration was determined using the method of Lowry et al (17).

To measure bone DNA content, the diaphyseal or metaphyseal tissues were shaken with $4.0 \mathrm{ml}$ of ice-cold $0.1 \mathrm{~N}$ $\mathrm{NaOH}$ solution for $24 \mathrm{~h}$ after homogenization of the bone tissues (18). After alkaline extraction, the samples were centrifuged at $1000 \mathrm{x} \mathrm{g}$ for $5 \mathrm{~min}$, and the supernatant was determined using the method of Ceriotti (19) and expressed as the amount of DNA (mg)/g wet weight of bone tissue.

Statistical analysis. Data were expressed as the mean \pm SEM. Statistical differences were analyzed using the Student's t-test. A p-value $<0.05$ was considered to indicate a statistically significant difference. The analysis of variance (ANOVA) multiple comparison test was used to compare the treatment groups.

\section{Results}

Effects of administration of HCA on serum biochemical components in STZ-diabetic rats. Rats received a single subcutaneous administration of STZ $(6.0 \mathrm{mg} / 100 \mathrm{~g}$ body weight), and the animals were orally administered HCA $(0.25,0.5$, or $1.0 \mathrm{mg} / 100 \mathrm{~g}$ body weight) once daily for 14 days. The body weight of the animals was significantly decreased 14 days after administration of STZ, but this reduction was significantly prevented after administration of HCA $(0.25,0.5$, or $1.0 \mathrm{mg} / 100 \mathrm{~g})$ for 14 days (Fig. 1$)$.

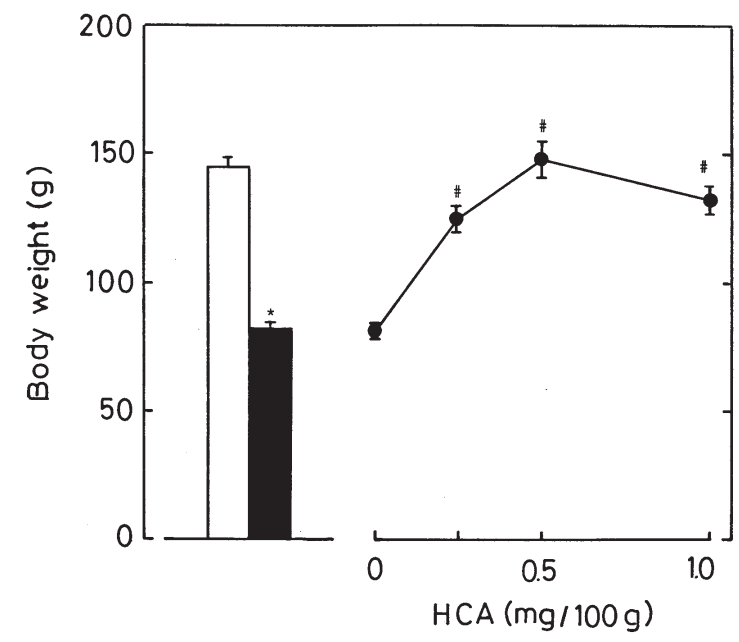

Figure 1. Effects of administration of $p$-hydroxycinnamic acid (HCA) on the change in body weight in STZ-diabetic rats. Rats received a single subcutaneous administration of STZ $(6.0 \mathrm{mg} / 100 \mathrm{~g}$ body weight), and $3 \mathrm{~h}$ later the animals were orally administered either vehicle (corn oil) or HCA (0.25, 0.5 , or $1.0 \mathrm{mg} / 100 \mathrm{~g}$ body weight) once daily for 14 days. Animals were sacrificed $24 \mathrm{~h}$ after the last administration. Each value is the mean $\pm \mathrm{SEM}$ of six rats. ${ }^{*} \mathrm{p}<0.01$ compared with the control (none) value; ${ }^{*} \mathrm{p}<0.01$ comparing the control value with the STZ treatment. White bar, control; black bar, STZ diabetes.
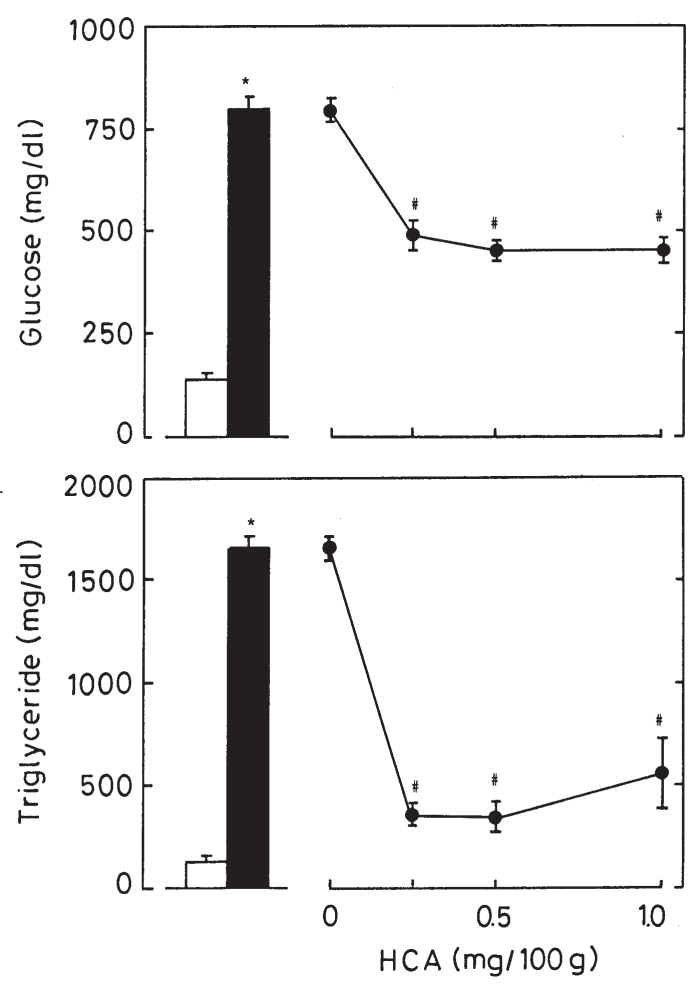

Figure 2. Effects of administration of $p$-hydroxycinnamic acid (HCA) on the change in glucose and triglyceride concentrations in STZ-diabetic rats. The administration procedure is described in the legend of Fig. 1. Each value is the mean \pm SEM of six rats. ${ }^{*} \mathrm{p}<0.01$ compared with the control (none) value; ${ }^{*} \mathrm{p}<0.01$ comparing the control value with the STZ treatment. White bars, control; black bars, STZ diabetes.

The serum glucose and triglyceride levels were markedly elevated in STZ-administered rats, indicating that the administration induced a diabetic state. These increases were 

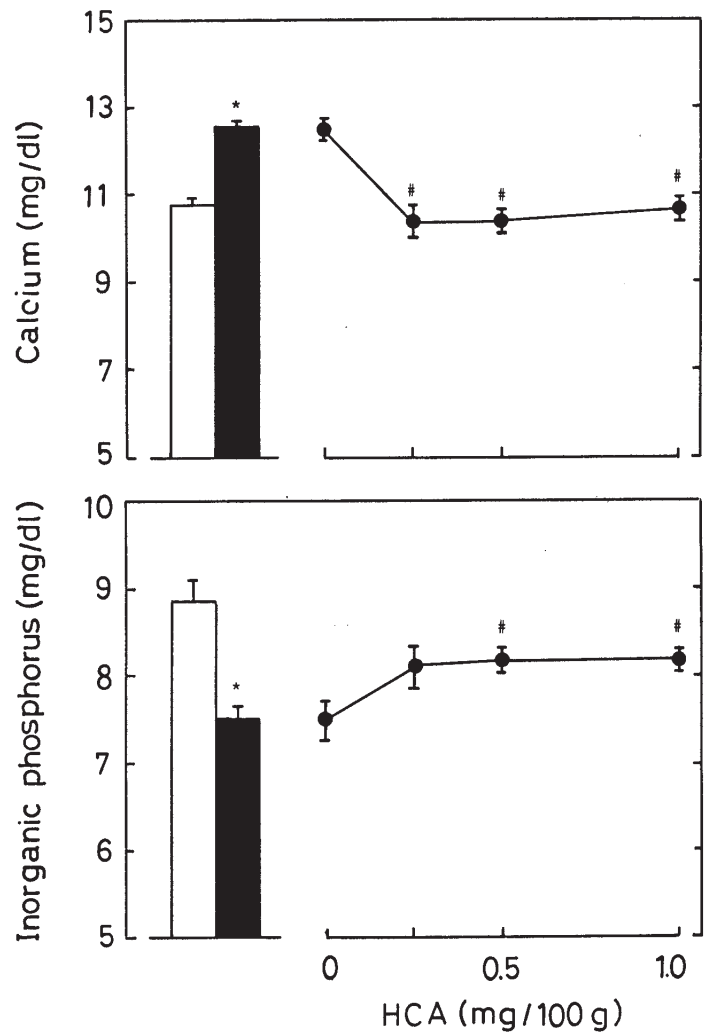

Figure 3. Effects of administration of $p$-hydroxycinnamic acid (HCA) on the change in calcium and inorganic phosphorus concentrations in STZ-diabetic rats. The administration procedure is described in the legend of Fig. 1. Each value is the mean \pm SEM of six rats. ${ }^{*} \mathrm{p}<0.01$ compared with the control (none) value; ${ }^{\#} \mathrm{p}<0.01$ comparing the control value with the STZ treatment. White bars, control; black bars, STZ diabetes.

significantly prevented after administration of HCA $(0.25$, 0.5 , or $1.0 \mathrm{mg} / 100 \mathrm{~g}$ ) for 14 days (Fig. 2).

The serum calcium levels were significantly increased after STZ administration (Fig. 3), and the increase was significantly prevented after administration of HCA $(0.25$, 0.5 or $1.0 \mathrm{mg} / 100 \mathrm{~g}$ ) for 14 days. Serum inorganic phosphorus levels were also significantly decreased 14 days after STZ administration (Fig. 3), and this decrease was significantly prevented after administration of HCA $(0.5$ or $1.0 \mathrm{mg} / 100 \mathrm{~g}$ ) for 14 days.

Effects of administration of HCA on bone components in STZdiabetic rats. The calcium content in the femoral-diaphyseal and -metaphyseal tissues of rats was significantly decreased 14 days after the administration of STZ $(6.0 \mathrm{mg} / 100 \mathrm{~g})$ (Fig. 4), and the decrease was significantly prevented after administration of HCA $(0.25,0.5$, or $1.0 \mathrm{mg} / 100 \mathrm{~g})$ for 14 days.

The alkaline phosphatase activity in femoral tissues was also significantly decreased in STZ-diabetic rats (Fig. 5), and the decrease in the diaphyseal tissues was significantly prevented after administration of HCA $(0.5$ or $1.0 \mathrm{mg} / 100 \mathrm{~g}$ ) for 14 days. The dose of HCA $(0.25,0.5$, or $1.0 \mathrm{mg} / 100 \mathrm{~g})$ for 14 days did not have a significant preventive effect on the decrease in metaphyseal alkaline phosphatase activity in STZdiabetic rats.

The DNA content in the femoral-diaphyseal tissues was significantly decreased in STZ-diabetic rats (Fig. 6), and the decrease was significantly prevented after administration of HCA $(0.25,0.5$, or $1.0 \mathrm{mg} / 100 \mathrm{~g})$ for 14 days. The metaphyseal DNA content was not significantly changed in STZdiabetic rats. Administration of $\mathrm{HCA}(0.25,0.5$, or $1.0 \mathrm{mg}$ / $100 \mathrm{~g}$ ) for 14 days caused a significant increase in metaphyseal DNA content in STZ-diabetic rats.

\section{Discussion}

The effects of cinnamic acid and other related phytocomponent compounds on bone metabolism have not yet been clarified. Recently, we found that $p$-hydroxycinnamic acid (HCA) stimulated bone formation and inhibited bone resorption in vitro (10), and that this compound had an inhibitory effect on various bone-resorbing factor-induced osteoclast-like cell formation in mouse bone marrow culture in vitro (11). Moreover, oral administration of HCA had an anabolic effect on bone components in the femoral tissues of

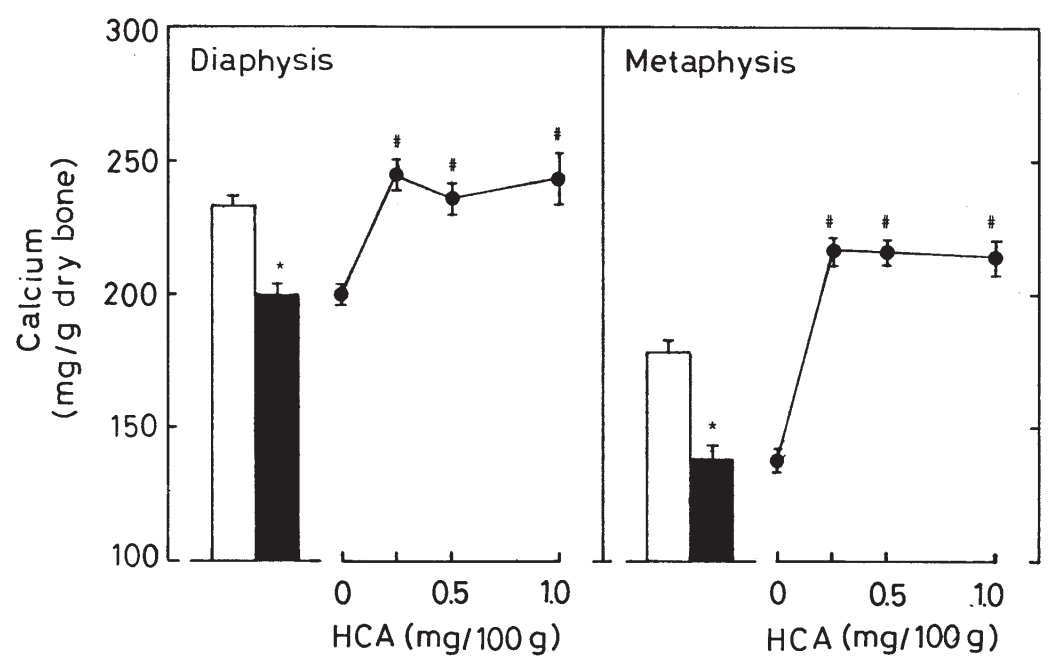

Figure 4. Effects of administration of $p$-hydroxycinnamic acid (HCA) on the change in calcium content in the femoral-diaphyseal and -metaphyseal tissues of STZ-diabetic rats. The administration procedure is described in the legend of Fig. 1. Each value is the mean \pm SEM of six rats. * $<<0.01$ comparing with the control (none) value; ${ }^{\#} \mathrm{p}<0.01$ comparing the control value with the STZ treatment. White bars, control; black bars, STZ diabetes. 


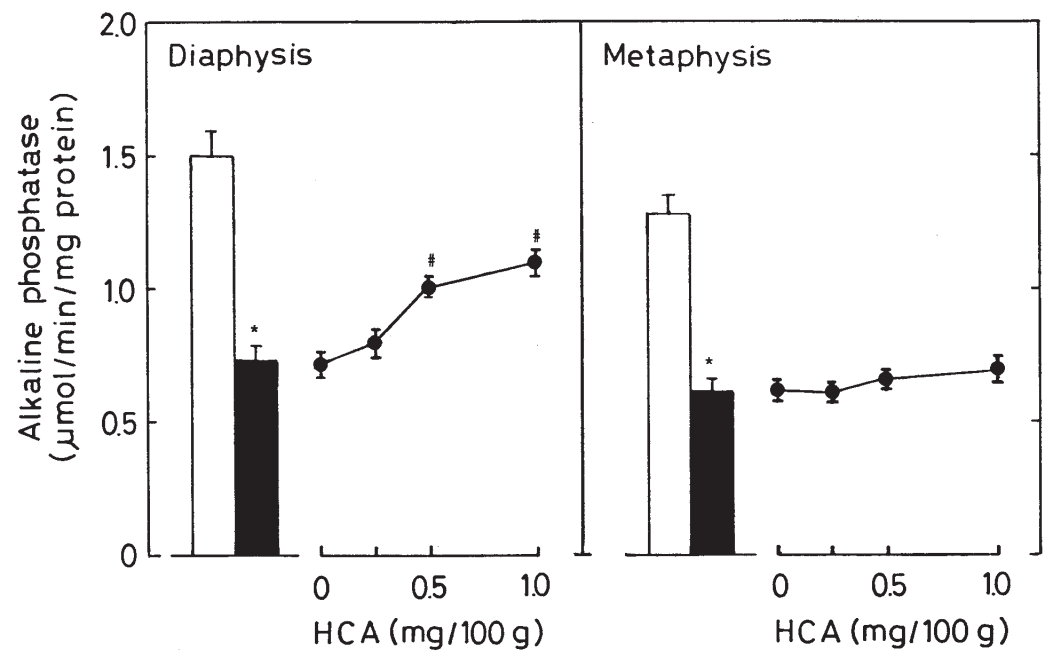

Figure 5. Effects of administration of $p$-hydroxycinnamic acid (HCA) on the change in alkaline phosphatase activity in the femoral-diaphyseal and -metaphyseal tissues of STZ-diabetic rats. The administration procedure is described in the legend of Fig. 1 . Each value is the mean \pm SEM of six rats. ${ }^{*} \mathrm{p}<0.01$ comparing with the control (none) value; ${ }^{*} \mathrm{p}<0.01$ comparing the control value with the STZ treatment. White bars, control; black bars, STZ diabetes.

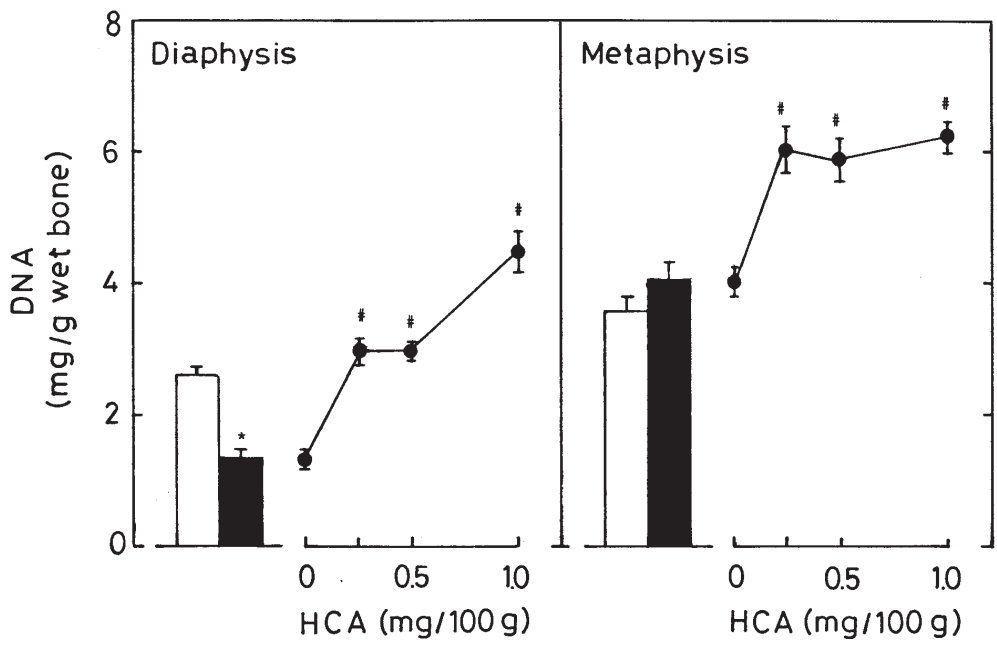

Figure 6. Effects of administration of $p$-hydroxycinnamic acid (HCA) on the change in DNA content in the femoral-diaphyseal and -metaphyseal tissues of STZ-diabetic rats. The administration procedure is described in the legend of Fig. 1. Each value is the mean \pm SEM of six rats. ${ }^{*}$ p $<0.01$ comparing with the control (none) value; ${ }^{*} \mathrm{p}<0.01$ comparing the control value with the STZ treatment. White bars, control; black bars, STZ diabetes.

rats in vivo (12). This study was undertaken to determine whether HCA has a preventive effect on bone loss in STZdiabetic rats.

Oral administration of HCA to STZ-diabetic rats was found to have a preventive effect on the decrease in body weight and the increase in serum glucose and triglyceride levels induced in the diabetic state. This is a novel finding. Intake of HCA has a partially restorative effect on serum biochemical findings involving diabetes in vivo. HCA may have a restorative role in the prevention of diabetic states.

The serum calcium level was found to increase in STZdiabetic rats. Intestinal calcium absorption has been shown to be impaired in the diabetic state (20-22). The increase in serum calcium concentration in STZ-diabetic rats may result from the release of calcium from bone tissues; the femoral calcium content was found to decrease markedly in STZdiabetic rats. Oral administration of HCA to these rats had a significant preventive effect on hypercalcemia and bone calcium loss in the diabetic state. Intake of HCA may thus have an inhibitory effect on bone resorption in these rats.

Alkaline phosphatase activity in the femoral tissues was found to decrease in STZ-diabetic rats. This enzyme participates in osteoblastic mineralization (23). The femoral alkaline phosphatase activity was significantly decreased in these rats, suggesting that osteoblastic bone mineralization is impaired in the diabetic state. The decrease in femoraldiaphyseal alkaline phosphatase activity in STZ-diabetic rats was significantly prevented after administration of HCA. Presumably, intake of HCA has a stimulatory effect on osteoblastic bone formation in this state.

HCA has been shown to increase DNA content in rat femoral tissues in vitro (10) and in vivo (12). Oral administration of HCA caused a significant increase in DNA content in the femoral-diaphyseal and -metaphyseal tissues of STZ-diabetic rats. DNA content in bone tissues is an index of the number of existing bone cells (24). It is speculated that 
HCA stimulates bone cells including osteoblastic cells in the diaphyseal and metaphyseal tissues of STZ-diabetic rats in vivo. This may be partly attributed to the increase in bone calcium content in STZ-diabetic rats.

Oral administration of HCA was found to have a preventive effect on bone loss in the STZ-diabetic state. HCA may have a role in the prevention of osteoporosis. Additional study is warranted using the ovariectomized rat, an animal model of osteoporosis, to further elucidate the present results.

In conclusion, it has been shown that the intake of HCA has a preventive effect on diabetic-induced bone loss, and also has a partially preventive effect on the increase in serum glucose and triglyceride levels in diabetes in vivo.

\section{References}

1. Nishimoto SK, Chang C-H, Gendler E, Stryker WF and Nimni ME: The effect of aging on bone formation in rats: Biochemical and histological evidence for decreased bone formation capacity. Calcif Tissue Int 37: 617-624, 1985.

2. Schapia C, Slinn S, Sarid M, Mokadi S, Kabala A and Slibermann M: Calcium and vitamin D enriched diets increase and preserve vertebral mineral content in aging laboratory rats. Bone 16: 575-582, 1995.

3. Wild RA, Buchamain JR, Myers C and Demers LM: Declining adrenal androgen: an association with bone loss in aging women. Proc Soc Exp Biol Med 186: 335-360, 1987.

4. Cooper C and Melton J III: Epidemiology of osteoporosis. Trends Endocrinol Metab 3: 1395-1445, 1996.

5. Bonjour J-P, Schurch M-A and Rozzori R: Nutritional aspects of hip fractures. Bone 18: 1395-1445, 1996.

6. Yamaguchi M: Isoflavone and bone metabolism: Its cellular mechanism and preventive role in bone loss. J Health Sci 48: 209-222, 2002.

7. Yamaguchi M: Regulatory mechanism of food factors in bone metabolism and prevention of osteoporosis. Yakugaku Zasshi 126: 1117-1137, 2006.

8. Lee M-K, Park E-M, Bok S-H, Jung UJ, Kim J-Y, Park YB, Huh T-L, Kwon O-S and Choi M-S: Two cinnamate derivatives produce similar alteration in mRNA expression and activity of antioxidant enzymes in rats. J Biochem Mol Toxicol 17: 255-262, 2003.

9. Luceri C, Guglielmi F, Lodovici M, Giannimi L, Messerini L and Dolara P: Plant phenolic 4-coumaric acid protects against intestinal inflammation in rats. Scand J Gastroenterol 39: 1128-1133, 2004.
10. Lai YL and Yamaguchi M: Phytocomponent $p$-hydroxycinnamic acid stimulates bone formation and inhibits bone resorption in rat femoral tissues in vitro. Mol Cell Biochem 292: 45-52, 2006

11. Lai YL and Yamaguchi M: Phytocomponent $p$-hydroxycinnamic acid inhibits osteoclast-like cell formation in mouse bone marrow cultures. Int J Mol Med 19: 123-128, 2007.

12. Lai YL and Yamaguchi M: Oral administration of phytocomponent $p$-hydroxycinnamic acid has anabolic effects on bone calcification in femoral tissues of rats in vivo. J Health Sci 52: 308-312, 2006.

13. Shires R, Teitelbaum SL, Bergfeld MA, Fallom MD, Statopolsky E and Avioli LV: The effect of streptozotocininduced chronic diabetes mellitus on bone and mineral homeostasis in the rat. J Lab Clin Med 97: 231-240, 1981.

14. Bollen M, Miralpeix M, Venture F, Toth B, Bartrons R and Stalmans W: Oral administration of vanadate to streptozotocindiabetic rats restores the glucose-induced activation of liver glycogen synthase. Biochem J 267: 269-271, 1990.

15. Yamaguchi M, Oishi $\mathrm{H}$ and Suketa $\mathrm{Y}$ : Stimulatory effect of zinc on bone formation in tissue culture. Biochem Pharmacol 36: 4007-4012, 1987.

16. Walter K and Schutt C: Acid and alkaline phosphatase in serum. In: Methods of Enzymatic Analysis. Bergmyer HU (ed). Vol. 1-2. Academic Press, New York, pp856-860, 1974.

17. Lowry OH, Rosenbrough NJ, Farr AL and Randall RJ: Protein measurement with the Folin phenol reagent. J Biol Chem 193: 265-273, 1951.

18. Flanagan B and Nichols G Jr: Metabolic studies of bone in vitro. VI. Collagen biosynthesis by surviving bone fragment in vitro. $\mathrm{J}$ Biol Chem 237: 3386-3789, 1962.

19. Ceriotti G: Determination of nucleic acid in animal tissues. J Biol Chem 241: 39-77, 1955.

20. Levin ME, Boissesu VC and Avioli LV: Effect of diabetes mellitus on bone mass in juvenile and adult-onset diabetes. $\mathrm{N}$ Engl J Med 294: 241-245, 1976.

21. Schneider LE and Schel HP: Experimental diabetes reduces circulating 1,25-dihydroxyvitamin D in the rat. Science 196: 1452-1454, 1977.

22. Nyomba BL, Verhaeghe J, Thomasser M, Lissens W and Bouillon R: Bone mineral homeostasis in spontaneously diabetic BB rats. I. Abnormal vitamin D metabolism and impaired active intestinal calcium absorption. Endocrinology 124: 565-572, 1980.

23. Majeska RJ and Wuthier RE: Studies on matrix vesicles isolated from chick epiphyseal cartilage. Association of pyrophosphate and ATPase activities with alkaline phosphatase. Biochim Biophys Acta 391: 51-60, 1975.

24. Canalis E, Centrella M, Bunch W and McCarthy TL: Insulinlike growth factor-I mediates selective anabolic effects of parathyroid hormone in bone cultures. J Clin Invest 83: 60-65, 1989. 